\title{
Transitions from Temporary to Permanent Work in Canada: Who Makes the Transition and Why?
}

\author{
Tony Fang $\cdot$ Fiona MacPhail
}

\begin{abstract}
The focus of this paper is on a microeconomic analysis of the annual transition rate from temporary to permanent work of individual workers in Canada for the period 1999-2004. Given that a large proportion of temporary employment is involuntary, an understanding of the factors associated with the transition to permanent work may inform public policy. Factors associated with the transition, namely, human capital, household structures and labour market segmentation are analyzed using data from the Statistics Canada's Survey of Labour and Income Dynamics (SLID) for the period 1999-2004, limited to paid workers aged 20-64 years, excluding students. Among the key factors associated with the transitions are younger age and low unemployment rates. The analysis adds to the Canadian and international literature on transitions from temporary to permanent work.
\end{abstract} Keywords Transition rates $\cdot$ Temporary $\cdot$ Permanent jobs $\cdot$ Labour market flexibility .
Canada

\section{Introduction}

Temporary work in Canada accounts for about $10 \%$ of total employment in 2005, thus in terms of incidence, Canada falls between the US at 5\%, the UK at 7\%, and Spain at 33\%. ${ }^{1}$ Temporary work is defined generally as work undertaken without a contract or with a ${ }^{1}$ Estimates for the UK and Spain are from Booth et al. (2002a) and the estimate for the US is from Polikva
(1996).

T. Fang (两)

School of Administrative Studies, Atkinson Faculty of Liberal and Professional Studies,

York University, 4700 Keele Street, Toronto, ON, Canada M3J 1P3

e-mail: tonyfang@yorku.ca

F. MacPhail

Economics Program, University of Northern British Columbia, 3333 University Way, Prince George,
BC, Canada V2N 4Z9

e-mail: macphail@unbc.ca 
contract of less than 6 months and this type of employment is most often involuntary and associated with greater economic insecurity than permanent work. Temporary work is associated with lower pay, lower satisfaction, less job-related training, and long-run wage penalties, compared to permanent work (for Canada see Fuller and Vosko 2008; for the UK, see Booth et al. 2002b; for Australia, see Gaston and Timcke 1999). In Canada, people with full-time temporary jobs have lower annual work hours, hourly earnings, annual earnings, and family income compared to people with permanent jobs (Kapsalis and Tourigny 2005; Galarneau 2005). Further, workers with temporary employment are unlikely to be protected by the standard employment regulations affecting severance, statutory holiday and pay, and other minimum working conditions (Campbell and Burgess 2001).

The involuntary nature of temporary work is plausible given the relatively low wages and insecurity compared to permanent work. ${ }^{2}$ In addition, the extent of the involuntary nature is indicated by the percentage of temporary workers reporting that they have taken temporary work because they are unable to find permanent work; for example, $85 \%$ of fixed-term workers are estimated to be involuntary in Spain (Amuedo-Dolantes 2000), and between 56\% and 64\% (depending upon the definition of temporary) in the US (Polivka 1996). ${ }^{3}$

Despite the costs to workers of temporary work, this form of work has increased in Canada, as in other OECD countries. In Canada, temporary work increased from $7 \%$ to 10\% between 1989 and 2005 (Vosko et al. 2003). Temporary work in Australia increased from $15.8 \%$ to $24.3 \%$ between 1984 and 1994 (Gaston and Timcke 1999); fixed-term contracts increased from $10 \%$ to $15.5 \%$ in the Sweden during the 1990s (Booth et al. 2002a). ${ }^{4}$ Further, in Canada, the increase in temporary work is likely greater than these aggregate percentages indicate given that among new hires, the percentage of temporary employment in total employment has increased substantially (Morissette and Johnson 2005). The increased prevalence of temporary work has been attributed to technological change, industrial structural change, and competitive pressures and uncertain product markets associated with globalization (Wiens-Tuers 2001; Morissette and Johnson 2005), along with the adoption of labour market policies that are intended to "deregulate" labour markets and to make them more "flexible" (Amuedo-Dorantes 2000; MacPhail and Bowles 2008).

If most workers make the transition from temporary to permanent work then the costs of temporary work in terms of low economic security are less of problem from an individual perspective, as well as that of society. High transition rates from temporary to permanent work, suggest that temporary jobs may serve as "stepping stones" to permanent jobs. As Booth et al. (2002a, b) for the UK have argued, one form of temporary work, that of fixedterm contracts, may provide a stepping stone to permanent jobs, but other forms of

\footnotetext{
2 Temporary work may be chosen because it offers an opportunity to better balance work and family responsibilities (for a given set of care options and constraints), and in a limited set of circumstances, temporary work may be both high paying and personally rewarding. For the majority of temporary workers, however, this type of work is undertaken involuntarily.

${ }^{3}$ It is not possible to estimate the percentage of involuntary temporary workers in Canada because such a question as used in other countries about why workers accept the temporary work is not included the Canadian nationally representative data sets.

${ }^{4}$ Note that Australians use the dichotomy of casual and permanent, where casual refers to jobs not covered by standard employment benefits, such as paid sick and holiday leave'. Campbell and Burgess (2001, p. 180) also argue that Australian Bureau of Statistics "data on casual employees underestimate the number and proportion of temporary employees in Australia".). The term "casual" used in this paper and in other papers using European Labour Force Surveys, refers to a sub-category of the temporary category.
} 
temporary work, are better viewed as "dead ends" (see, also Gaston and Timcke 1999, for Australia, who conclude that casual jobs are more likely to be stepping stones).

In this paper, we undertake a microeconomic analysis of the transition from temporary to permanent work of individual workers in Canada for the period 1999-2004. ${ }^{5}$ Specifically, we determine the annual transition rate from temporary to permanent work, which workers are more likely to make the transition from temporary to permanent work, and demand side factors associated with the transition. We address these issues using data from the Statistics Canada's Survey of Labour and Income Dynamics (SLID) for the period 1999-2004. Our data analysis is limited to paid workers aged 20-64 years, excluding students.

This analysis adds to the Canadian and international literature on transitions from temporary to permanent work. Annual transition rates from temporary to permanent work vary considerably among countries with the annual transition rate in Spain estimated to be $12 \%$ (Amuedo-Dorantes 2000) and over 56\% in the US for workers in the temporary help agency category (Segal and Sullivan 1997). ${ }^{6}$ As far as we know, there is no multivariate analysis of transition rates from temporary to permanent work for Canada, although Kapsalis and Tourigny (2005) document the annual transition rate from non-standard to standard work but not the associated factors. This analysis is complementary to the analyses of transitions from part-time to full-time work transitions for Canada (Noreau 2000) and other countries (O'Reilly and Bothfeld 2002 for the UK and Germany; Blank 1994 for the US), as well, the transition from low wage to higher wage employment (for Canada, see Janz 2004).

In the next section, we review the international econometric evidence of the transition from temporary to permanent work. In Sect. 3, our empirical approach for analyzing the dynamics of transition in Canada is discussed, and the results are presented in Sect. 4. A summary of the paper and the implications of the results are provided in Sect. 5.

\section{International Evidence on the Transition from Temporary to Permanent Work}

This selective review of the international literature on the transition from temporary to permanent work considers three issues: measurement choices associated with temporary work that affect the transition estimates; the factors affecting transition; and the econometric techniques used for modeling the transition. The implications for our paper are highlighted at the end of this section.

First, while we focus on the factors related to the transition rates from temporary to

measurement choices affect estimates of the transition rate. Regarding the length of the transition period, Gaston and Timcke ( ), for Australia, show clearly that the transition rates increase with the length of the transition period considered. There also exists considerable variation in the transition rates depending on the type of temporary work being

from seasonal or casual jobs (Booth et al. ).

\footnotetext{
This paper complements research at the aggregate level on the relationship between temporary work, unemployment, and employment protection (see, for example, Baker et al. ).

See also Booth et al. ( ) for Britain; Blanchard and Landier ( ) for France; Holmlund and Storrie ( ) for Sweden.
} 


\title{
Transitions from Temporary to Permanent Work in Canada: Who Makes the Transition and Why?
}

\author{
Tony Fang $\cdot$ Fiona MacPhail
}

\begin{abstract}
The focus of this paper is on a microeconomic analysis of the annual transition rate from temporary to permanent work of individual workers in Canada for the period 1999-2004. Given that a large proportion of temporary employment is involuntary, an understanding of the factors associated with the transition to permanent work may inform public policy. Factors associated with the transition, namely, human capital, household structures and labour market segmentation are analyzed using data from the Statistics Canada's Survey of Labour and Income Dynamics (SLID) for the period 1999-2004, limited to paid workers aged 20-64 years, excluding students. Among the key factors associated with the transitions are younger age and low unemployment rates. The analysis adds to the Canadian and international literature on transitions from temporary to permanent work.
\end{abstract}

Keywords Transition rates $\cdot$ Temporary $\cdot$ Permanent jobs $\cdot$ Labour market flexibility · Canada

\section{Introduction}

Temporary work in Canada accounts for about $10 \%$ of total employment in 2005 , thus in terms of incidence, Canada falls between the US at $5 \%$, the UK at $7 \%$, and Spain at $33 \%{ }^{1}$ Temporary work is defined generally as work undertaken without a contract or with a

${ }^{1}$ Estimates for the UK and Spain are from Booth et al. (2002a) and the estimate for the US is from Polikva (1996).

T. Fang $(\square)$

School of Administrative Studies, Atkinson Faculty of Liberal and Professional Studies,

York University, 4700 Keele Street, Toronto, ON, Canada M3J 1P3

e-mail: tonyfang@yorku.ca

F. MacPhail

Economics Program, University of Northern British Columbia, 3333 University Way, Prince George,

BC, Canada V2N 4 Z9

e-mail: macphail@unbc.ca 
contract of less than 6 months and this type of employment is most often involuntary and associated with greater economic insecurity than permanent work. Temporary work is associated with lower pay, lower satisfaction, less job-related training, and long-run wage penalties, compared to permanent work (for Canada see Fuller and Vosko 2008; for the UK, see Booth et al. 2002b; for Australia, see Gaston and Timcke 1999). In Canada, people with full-time temporary jobs have lower annual work hours, hourly earnings, annual earnings, and family income compared to people with permanent jobs (Kapsalis and Tourigny 2005; Galarneau 2005). Further, workers with temporary employment are unlikely to be protected by the standard employment regulations affecting severance, statutory holiday and pay, and other minimum working conditions (Campbell and Burgess 2001).

The involuntary nature of temporary work is plausible given the relatively low wages and insecurity compared to permanent work. ${ }^{2}$ In addition, the extent of the involuntary nature is indicated by the percentage of temporary workers reporting that they have taken temporary work because they are unable to find permanent work; for example, $85 \%$ of fixed-term workers are estimated to be involuntary in Spain (Amuedo-Dolantes 2000), and between 56\% and 64\% (depending upon the definition of temporary) in the US (Polivka 1996). ${ }^{3}$

Despite the costs to workers of temporary work, this form of work has increased in Canada, as in other OECD countries. In Canada, temporary work increased from $7 \%$ to 10\% between 1989 and 2005 (Vosko et al. 2003). Temporary work in Australia increased from $15.8 \%$ to $24.3 \%$ between 1984 and 1994 (Gaston and Timcke 1999); fixed-term contracts increased from $10 \%$ to $15.5 \%$ in the Sweden during the 1990s (Booth et al. 2002a). ${ }^{4}$ Further, in Canada, the increase in temporary work is likely greater than these aggregate percentages indicate given that among new hires, the percentage of temporary employment in total employment has increased substantially (Morissette and Johnson 2005). The increased prevalence of temporary work has been attributed to technological change, industrial structural change, and competitive pressures and uncertain product markets associated with globalization (Wiens-Tuers 2001; Morissette and Johnson 2005), along with the adoption of labour market policies that are intended to "deregulate" labour markets and to make them more "flexible" (Amuedo-Dorantes 2000; MacPhail and Bowles 2008).

If most workers make the transition from temporary to permanent work then the costs of temporary work in terms of low economic security are less of problem from an individual perspective, as well as that of society. High transition rates from temporary to permanent work, suggest that temporary jobs may serve as "stepping stones" to permanent jobs. As Booth et al. (2002a, b) for the UK have argued, one form of temporary work, that of fixedterm contracts, may provide a stepping stone to permanent jobs, but other forms of

\footnotetext{
${ }^{2}$ Temporary work may be chosen because it offers an opportunity to better balance work and family responsibilities (for a given set of care options and constraints), and in a limited set of circumstances, temporary work may be both high paying and personally rewarding. For the majority of temporary workers, however, this type of work is undertaken involuntarily.

${ }^{3}$ It is not possible to estimate the percentage of involuntary temporary workers in Canada because such a question as used in other countries about why workers accept the temporary work is not included the Canadian nationally representative data sets.

${ }^{4}$ Note that Australians use the dichotomy of casual and permanent, where casual refers to jobs not covered by standard employment benefits, such as paid sick and holiday leave'. Campbell and Burgess (2001, p. 180) also argue that Australian Bureau of Statistics "data on casual employees underestimate the number and proportion of temporary employees in Australia".). The term "casual" used in this paper and in other papers using European Labour Force Surveys, refers to a sub-category of the temporary category.
} 
temporary work, are better viewed as "dead ends" (see, also Gaston and Timcke 1999, for Australia, who conclude that casual jobs are more likely to be stepping stones).

In this paper, we undertake a microeconomic analysis of the transition from temporary to permanent work of individual workers in Canada for the period 1999-2004. ${ }^{5}$ Specifically, we determine the annual transition rate from temporary to permanent work, which workers are more likely to make the transition from temporary to permanent work, and demand side factors associated with the transition. We address these issues using data from the Statistics Canada's Survey of Labour and Income Dynamics (SLID) for the period 1999-2004. Our data analysis is limited to paid workers aged 20-64 years, excluding students.

This analysis adds to the Canadian and international literature on transitions from temporary to permanent work. Annual transition rates from temporary to permanent work vary considerably among countries with the annual transition rate in Spain estimated to be $12 \%$ (Amuedo-Dorantes 2000) and over 56\% in the US for workers in the temporary help agency category (Segal and Sullivan 1997). ${ }^{6}$ As far as we know, there is no multivariate analysis of transition rates from temporary to permanent work for Canada, although Kapsalis and Tourigny (2005) document the annual transition rate from non-standard to standard work but not the associated factors. This analysis is complementary to the analyses of transitions from part-time to full-time work transitions for Canada (Noreau 2000 ) and other countries (O'Reilly and Bothfeld 2002 for the UK and Germany; Blank 1994 for the US), as well, the transition from low wage to higher wage employment (for Canada, see Janz 2004).

In the next section, we review the international econometric evidence of the transition from temporary to permanent work. In Sect. 3, our empirical approach for analyzing the dynamics of transition in Canada is discussed, and the results are presented in Sect. 4. A summary of the paper and the implications of the results are provided in Sect. 5.

\section{International Evidence on the Transition from Temporary to Permanent Work}

This selective review of the international literature on the transition from temporary to permanent work considers three issues: measurement choices associated with temporary work that affect the transition estimates; the factors affecting transition; and the econometric techniques used for modeling the transition. The implications for our paper are highlighted at the end of this section.

First, while we focus on the factors related to the transition rates from temporary to permanent work specific to Canada, this needs to be set within an understanding of how measurement choices affect estimates of the transition rate. Regarding the length of the transition period, Gaston and Timcke (1999), for Australia, show clearly that the transition rates increase with the length of the transition period considered. There also exists considerable variation in the transition rates depending on the type of temporary work being considered. For example, in the UK, for workers on fixed-term contracts the transition rate to permanency is significantly higher, compared to the transition rate to permanent work from seasonal or casual jobs (Booth et al. 2002a, b).

\footnotetext{
${ }^{5}$ This paper complements research at the aggregate level on the relationship between temporary work, unemployment, and employment protection (see, for example, Baker et al. 2004).

${ }^{6}$ See also Booth et al. (2002b) for Britain; Blanchard and Landier (2001) for France; Holmlund and Storrie (2002) for Sweden.
} 
Second, the transition from temporary to permanent work over a period of time has been analyzed in terms of various supply and demand side factors, similar to the factors used to explain the transition from part-time to full-time work. O'Reilly and Bothfield (2002) in a paper analyzing the transition from part-time to full-time work distinguish among three sets of factors, namely human capital, household structures, and segmentation factors, and we adapt this threefold theoretical categorization for reviewing the empirical results of factors affecting the temporary to permanent work transitions.

From a human capital perspective, temporary workers with greater investments in human capital are more likely to make the transition to permanent work, given their relatively greater skills and commitment to the labour force. Thus, educational qualifications and work experience are positive predictors of the transition. Blank (1994), in the context of a US study of part-time-full-time work, notes that past work history is an important indicator of future transitions. Thus, a person currently employed in a full-time temporary job may be more likely than someone with a part-time temporary position to make the transition to permanent work. Gaston and Timcke (1999) demonstrate that for the youth, non-student population in Australia, part-time casuals have a $10.6 \%$ transition rate into full-time permanent work compared to $27.4 \%$ for full-time casuals. Likewise, a person who previously held a full-time permanent job (before the temporary job) is more likely to make the transition to permanent work, than a person who has never held a permanent job. Chalmers and Kalb (2001) show a similar affect for unemployment to permanent employment transition.

In terms of household structures, the presence of children may reduce the likelihood of the transition. In cross-country studies, the effect of children on female labour force participation depends on the availability and quality of child care facilities, maternity leave and maternity benefits. However, at a given point in time and in one location, temporary work may be a constrained choice for women with children. The relationship between gender and transition rates is mixed: for Australia, Gaston and Timcke (1999) report that women have lower likelihood of transition, compared to men. However, Chalmers and Kalb (2001), also for Australia, report no gender differences. There may be significant interaction affects with household income and labour force status of the spouse. For example, women with unemployed spouses are less likely to move from temporary to permanent work, than women with employed spouses (Chalmers and Kalb 2001). With respect to income, high income households may be able to afford to keep one person marginally attached to the labour force, so income and transition are expected to be negatively related. For both men and women, younger workers are more likely to make the transition (Chalmers and Kalb 2001, for men in the UK, see Booth et al. 2002b).

Turning to the demand side and extrapolating from labour market segmentation theory, we expect that the transitions from temporary to permanent employment will vary among firms depending upon firm size, industry, occupation and degree of unionization. Following Doeringer and Piore (1971), large firms with sophisticated technologies are more likely to create internal labour markets, invest in firm-specific capital, and reward employees in order to retain them; therefore, we predict that temporary workers in large firms will have a greater likelihood of making the transition into permanent work, compared to temporary workers in small firms. ${ }^{7}$

With respect to industry, we hypothesize that certain industries will have relatively low rates of transition from temporary to permanent work. Industries such as agriculture and

\footnotetext{
${ }^{7}$ See Bentolila and Dolado (1994) on the existence of a dual labour market in Spain with permanent workers as insiders and temporary workers as outsiders.
} 
fishing, which rely to a greater extent on seasonal labour would have relatively low transition rates. Similarly, industries with fluctuating product demand are expected to have larger proportions of temporary workers and low transition rates. Empirical analyses have found that employment in the public and non-profit sectors, for women, is associated with lower transition rates (Booth et al. 2002b). Regions may also have different transition rates given regional differences in industrial structure. Rural areas for example, may have lower rates of transition given greater likelihood of the presence of agriculture.

We hypothesize that in occupations where it is difficult to assess individuals' productivities, temporary contracts may be used as a mechanism to evaluate individuals' performances and such occupations would be expected to have relatively higher incidences of temporary work. These occupations might also be expected to have relatively high transition rates.

It is unclear how unionization will affect transition rates from temporary to permanent work. One could hypothesize that unions might promote the conversion of temporary jobs into permanent ones, and thus, transition rates would be higher in unionized compared to non-unionized environments. Support for this hypothesis is provided by Gaston and Trimke (1999), for young workers in Australia, who find that union status increases the probability of moving into a permanent job. Alternatively, however, unions may negotiate better conditions for workers in temporary jobs and thus, there is a tendency for lower transition rates, compared to temporary jobs in non-unionized environments.

Comparative analyses of temporary work show that in some jurisdictions, temporary work exhibits an anti-cyclical pattern (Holmlund and Storrie 2002). Therefore, we predict that, with cross-sectional data, regions with high unemployment rates will have lower transition rates into permanent work.

Third, the main econometric method for estimating the transition from temporary to permanent work (or the reverse) is with a multinomial logit model controlling for factors affecting the transition (see for example Amuedo-Dorantes 2000; Gaston and Timcke 1999). The actual model specified varies in the literature given such measurement choices and determinants as noted above. Hazard models are used to examine the duration of the given state before exiting that state to a new state, for example, the movement from temporary to permanent work, taking into account the censoring of observations (see for example, Chalmers and Kalb 2001; Booth et al. 2002b).

The implications of this selective literature review for this paper are as follows. In terms of measurement choices, we focus on the annual transition rate in order to increase the comparability of our estimates with other studies, and we distinguish among transitions from each of the four types of temporary work to permanent work, given the heterogeneity of temporary work. Since we cannot isolate the involuntary temporary workers directly (since a related question in the Canadian dataset does not exist), we restrict the sample to workers between the ages of 20 and 64 years who are not full-time students since this is the group who are most likely to experience involuntary temporary work. Given that our main focus is on economic insecurity arising from employment, we examine mostly the transition from temporary to permanent employment and not the full set of possible transitions including temporary employment to unemployment, out-of-the labour force, or into selfemployment.

Second, hypotheses about the transition derived from the literature which are considered in this paper are as follows. In general, with respect to gender, women are expected to have lower transition rates than men, perhaps arising from household structures and women's greater responsibility for household work. With respect to type of temporary work, we expect higher rates of transition for temporary workers employed in fixed-term contracts 
compared to seasonal and casual contracts. Moving to factors associated with the transition, in terms of human capital, we expect temporary workers are more likely to make the transition to permanent work if: they have higher levels of education, more work experience, and preference for full-time work as indicated by multiple job holding. In terms of household structure, we expect temporary workers are more likely to make the transition to permanent work if: they have fewer children; are not disabled; and have lower family income. With respect to segmentation theory, we expect that workers are more likely to make the transition to permanent work if: they are employed in larger firms; are covered by a collective agreement; are not employed in primary industries such as agriculture and forestry; reside in provinces less influenced by primary industries; reside in an area with lower unemployment rates.

Third, we employ, as is common in the literature, a Probit model to examine the factors associated with the transition from temporary to permanent work.

\section{Empirical Approach and Data}

Our empirical approach is to estimate the determinants of year-over-year transition probabilities from temporary to permanent employment or vice versa, as shown in Eq. 1:

$$
\operatorname{Pr}\left(\operatorname{TRAN}_{\mathrm{it}}=1\right)=f\left(\alpha_{1} \mathrm{H}_{\mathrm{it}-1}+\alpha_{2} \mathrm{D}_{\mathrm{it}-1}+\alpha_{2} \mathrm{~S}_{\mathrm{it}-1}+u_{i t}\right)
$$

where $\operatorname{TRAN}_{\mathrm{it}}=1$ if individual $\mathrm{i}$ makes the transition from time $\mathrm{t}-1$ to time $\mathrm{t}$, and equals 0 otherwise. The independent variables are incorporated in three sets.

First, $\mathrm{H}_{\mathrm{it}-1}$ is a vector of controls for observable human capital factors for individual $\mathrm{i}$ in time $t-1$ such as education and labour market experience. Second, $D_{\text {it }-1}$ is a vector of controls for observable demographic and household factors for individual i in time $t-1$ such as age categories, marital status, and presence of children, along with variables to capture household income such as family income and relationship to major income earner in the household. In addition to gender, we also include disability status, aboriginal status and visible minority status. Third, $S_{\mathrm{it}-1}$ is a vector of controls for observable external factors related to segmentation of the labour market for individual $i$ in time $t-1$ such as province, rural-urban location, union/collective bargaining status, firm size, occupation, industry, economic conditions, multiple job holder; and $u_{i t}$ is a residual.

We also estimate the model separately for men and women given expected gender differences in human capital investments (although gender differences in human capital investments have narrowed over time) and occupational and industrial segregation. We also examine the transition rate model separately for different types of temporary work given that some forms of temporary work such as fixed term contracts may be used by employers for different reasons than seasonal temporary work. Booth et al. (2002a, b) point out that different types of temporary work may be associated with quite different amounts of specific human capital acquisition. Specifically, seasonal and casual jobs may be associated with lower levels of specific human capital acquisition compared to fixed term contracts. Further, different types of temporary jobs are used to varying degrees by industry and occupation.

We conduct the empirical transitional analysis using data from the Statistics Canada Survey of Labour and Income Dynamics (SLID) for the period 1999-2004. Temporary employment is defined in the SLID as work that has a predetermined end date or will end as soon as a specific project is completed. Temporary jobs are sub-classified into five groups: seasonal; term or contract, non-seasonal; casual; temporary-help agency; and other. 
The definition of temporary work is the same as used in the Labour Force Survey in Canada, and in other countries. Although, in the Canadian Labour Force Survey, the temporary-help agency sub-category is not included. Temporary work in the SLID is captured by the variable $\mathrm{CH}-\mathrm{Q} 040$ and a subsequent question allows the type of temporary work to be identified; the four categories used in this paper are seasonal, fixed-term, casual, and temporary-help agency. The SLID is a rich data set which provides information on the human capital, household structure, and segmentation factors, ${ }^{8}$ discussed in the literature review and noted above, which allow us to test the hypotheses about factors affecting the transition.

Our empirical strategy is based on a methodology of utilizing longitudinal data of the SLID to examine employment transition probabilities of individuals from being in temporary employment at time $t-1$ to being in permanent employment in time $t$. We combine five, 2-year panels (1999-2004) to conduct the transitional analysis of temporary work in order to derive sufficiently large sample sizes. Thus, the transitional probabilities derived from estimating Eq. 1 represent the average year-to-year probabilities for the period 1999-2004.

Equation 1 is estimated for individuals aged $20-64$ years, excluding students. Students are excluded since their work status may be related to their student status. The independent variables reflect the individual's response for their main job in time $t-1$. The descriptive statistics for the sample of temporary workers, aged 20-64 years of age, excluding students, for the pooled period 1999-2004 are presented in Appendix A.

\section{Empirical Analysis: Transition Rates and Associated Factors}

In this section, we provide an analysis of: (i) the characteristics of temporary workers; (ii) the annual transition rates from temporary to permanent work; and (iii) factors associated with the transition.

Table 1 below presents a profile of six mutually exclusive groups which are four types of temporary workers in 2002, and for comparison purposes, permanent workers divided into full-time/full-year and part-time (or part-year or both part-time and part-year) and the "other" sub-category of temporary work is excluded from Table 1 . The characteristics are for workers aged 16-69 years excluding students. As shown in Table 1, 11.9\% of workers have temporary employment; $3.3 \%$ of all workers are seasonal, $5.0 \%$ are on term contracts, $2.4 \%$ are casual workers, and $0.2 \%$ are employed by temporary-help agencies; and $1.0 \%$ are in the other temporary category (not shown in Table 1). Men are more likely to be in seasonal temporary work, compared to women; and women are more likely to be in the other three forms of temporary work, compared to men. Aboriginal people are more likely to be in seasonal work, than in permanent work, compared to non-aboriginal workers. Characteristics associated with being in temporary work are as follows: younger age; being single, separate, widowed; lower education; lower work experience; living in the Atlantic region; living in a rural area (for the seasonal category).

Table 2 presents estimates of the transition rates from temporary to permanent work, along with the reverse transition, by gender and for different types of temporary work. The estimates represent the percentage of workers who make the transition between two successive years, averaged over the five possible annual transitions between 1999 and 2004;

\footnotetext{
${ }^{8}$ The Master File of SLID contains the individual's employment insurance (EI) region. Information on the annual unemployment rate between 2000 and 2004 for each EI region was provided by HRSDC.
} 
Table 1 Distribution of permanent and temporary workers by selected characteristics (average proportions 2002)

\begin{tabular}{|c|c|c|c|c|c|c|}
\hline \multirow[t]{2}{*}{ Variable } & \multicolumn{2}{|l|}{ Permanent } & \multicolumn{4}{|c|}{ Temporary } \\
\hline & $\begin{array}{l}\text { Full time/ } \\
\text { full year } \\
\text { (1) }\end{array}$ & $\begin{array}{l}\text { Full time/ } \\
\text { part year } \\
\text { and part-time } \\
\text { (2) }\end{array}$ & Seasonal & Term & Casual & Temp-help \\
\hline Average probability & 0.684 & 0.197 & 0.033 & 0.050 & 0.024 & 0.002 \\
\hline Male & 0.569 & 0.407 & 0.684 & 0.462 & 0.359 & 0.483 \\
\hline Female & 0.431 & 0.593 & 0.316 & 0.538 & 0.641 & 0.517 \\
\hline Non-disabled & 0.848 & 0.817 & 0.791 & 0.832 & 0.832 & 0.854 \\
\hline Disabled & 0.152 & 0.183 & 0.209 & 0.168 & 0.168 & 0.146 \\
\hline Not aboriginal & 0.967 & 0.964 & 0.948 & 0.958 & 0.969 & 1.000 \\
\hline Aboriginal & 0.033 & 0.036 & 0.052 & 0.042 & 0.031 & 0.000 \\
\hline Not visible minority & 0.892 & 0.880 & 0.956 & 0.876 & 0.897 & 0.646 \\
\hline Visible minority & 0.108 & 0.120 & 0.044 & 0.124 & 0.103 & 0.354 \\
\hline Age $16-19$ & 0.004 & 0.023 & 0.033 & 0.026 & 0.053 & 0.000 \\
\hline Age $20-24$ & 0.045 & 0.096 & 0.098 & 0.097 & 0.093 & 0.174 \\
\hline Age $25-29$ & 0.106 & 0.115 & 0.110 & 0.140 & 0.091 & 0.024 \\
\hline Age $30-39$ & 0.284 & 0.272 & 0.230 & 0.257 & 0.216 & 0.215 \\
\hline Age $40-49$ & 0.333 & 0.240 & 0.253 & 0.245 & 0.208 & 0.231 \\
\hline Age $50-59$ & 0.197 & 0.188 & 0.200 & 0.176 & 0.209 & 0.336 \\
\hline Age $60-64$ & 0.027 & 0.045 & 0.069 & 0.040 & 0.086 & 0.019 \\
\hline Age $65-69$ & 0.004 & 0.021 & 0.008 & 0.019 & 0.044 & 0.000 \\
\hline Single, never married & 0.189 & 0.240 & 0.303 & 0.291 & 0.261 & 0.232 \\
\hline Married, common law & 0.704 & 0.651 & 0.584 & 0.585 & 0.634 & 0.737 \\
\hline Separated & 0.036 & 0.046 & 0.050 & 0.045 & 0.040 & 0.011 \\
\hline Divorced & 0.062 & 0.045 & 0.043 & 0.071 & 0.050 & 0.020 \\
\hline Widowed & 0.008 & 0.017 & 0.020 & 0.008 & 0.014 & 0.000 \\
\hline Number of children & 1.530 & 1.570 & 1.570 & 1.430 & 1.670 & 1.470 \\
\hline Less than high school grad. & 0.121 & 0.158 & 0.338 & 0.109 & 0.187 & 0.189 \\
\hline High school graduate & 0.281 & 0.281 & 0.303 & 0.232 & 0.290 & 0.278 \\
\hline Non-U. postsecondary certif. & 0.328 & 0.301 & 0.251 & 0.283 & 0.336 & 0.393 \\
\hline University degree or certificate & 0.206 & 0.184 & 0.033 & 0.307 & 0.125 & 0.050 \\
\hline Work experience (years) & 18.300 & 13.700 & 15.200 & 13.600 & 13.900 & 10.500 \\
\hline Ontario & 0.401 & 0.380 & 0.236 & 0.364 & 0.299 & 0.579 \\
\hline Newfoundland/Labrador & 0.014 & 0.015 & 0.084 & 0.028 & 0.024 & 0.000 \\
\hline Prince Edward Island & 0.004 & 0.004 & 0.024 & 0.008 & 0.007 & 0.004 \\
\hline Nova Scotia & 0.030 & 0.028 & 0.061 & 0.033 & 0.045 & 0.011 \\
\hline New Brunswick & 0.023 & 0.024 & 0.075 & 0.029 & 0.035 & 0.000 \\
\hline Quebec & 0.240 & 0.228 & 0.260 & 0.303 & 0.326 & 0.144 \\
\hline Manitoba & 0.038 & 0.035 & 0.023 & 0.026 & 0.028 & 0.035 \\
\hline Saskatchewan & 0.029 & 0.031 & 0.031 & 0.022 & 0.023 & 0.000 \\
\hline Alberta & 0.103 & 0.117 & 0.091 & 0.104 & 0.059 & 0.118 \\
\hline British Columbia & 0.119 & 0.138 & 0.115 & 0.083 & 0.155 & 0.110 \\
\hline Rural & 0.165 & 0.179 & 0.410 & 0.185 & 0.223 & 0.114 \\
\hline
\end{tabular}


Table 1 continued

\begin{tabular}{|c|c|c|c|c|c|c|}
\hline \multirow[t]{2}{*}{ Variable } & \multicolumn{2}{|l|}{ Permanent } & \multicolumn{4}{|l|}{ Temporary } \\
\hline & $\begin{array}{l}\text { Full time/ } \\
\text { full year } \\
\text { (1) }\end{array}$ & $\begin{array}{l}\text { Full time/ } \\
\text { part year } \\
\text { and part-time } \\
(2)\end{array}$ & Seasonal & Term & Casual & Temp-help \\
\hline Urban 0-99,999 & 0.230 & 0.242 & 0.281 & 0.225 & 0.244 & 0.255 \\
\hline Urban $100,000-499,999$ & 0.131 & 0.125 & 0.099 & 0.127 & 0.138 & 0.011 \\
\hline Urban 500,000 and higher & 0.475 & 0.453 & 0.210 & 0.463 & 0.394 & 0.620 \\
\hline Management occupation & 0.097 & 0.048 & 0.012 & 0.042 & 0.007 & 0.000 \\
\hline Business, finance, admin. & 0.208 & 0.182 & 0.070 & 0.217 & 0.173 & 0.301 \\
\hline Natural and applied science & 0.089 & 0.051 & 0.035 & 0.060 & 0.008 & 0.000 \\
\hline Health & 0.058 & 0.065 & 0.000 & 0.037 & 0.100 & 0.000 \\
\hline Social science & 0.069 & 0.071 & 0.008 & 0.180 & 0.083 & 0.000 \\
\hline Art, culture, recreation, sports & 0.017 & 0.020 & 0.019 & 0.033 & 0.027 & 0.000 \\
\hline Sales and service & 0.195 & 0.348 & 0.188 & 0.189 & 0.407 & 0.083 \\
\hline Trades, transport and equip. op. & 0.150 & 0.124 & 0.324 & 0.149 & 0.114 & 0.182 \\
\hline Primary occupations & 0.015 & 0.018 & 0.228 & 0.030 & 0.034 & 0.000 \\
\hline Processing, mfg., utilities & 0.102 & 0.073 & 0.115 & 0.060 & 0.045 & 0.434 \\
\hline Manufacturing industry & 0.200 & 0.123 & 0.140 & 0.087 & 0.069 & 0.179 \\
\hline Agriculture & 0.007 & 0.010 & 0.065 & 0.012 & 0.010 & 0.000 \\
\hline Forest, fish, mining, oil and gas & 0.019 & 0.017 & 0.132 & 0.021 & 0.008 & 0.000 \\
\hline Utilities & 0.012 & 0.005 & 0.008 & 0.015 & 0.003 & 0.000 \\
\hline Construction & 0.046 & 0.045 & 0.229 & 0.118 & 0.039 & 0.044 \\
\hline Trade & 0.141 & 0.185 & 0.053 & 0.080 & 0.215 & 0.058 \\
\hline Transportation, warehousing & 0.052 & 0.056 & 0.060 & 0.024 & 0.039 & 0.011 \\
\hline Finance, insurance, real estate & 0.061 & 0.055 & 0.009 & 0.038 & 0.042 & 0.000 \\
\hline Prof., scientific, tech. service & 0.058 & 0.048 & 0.022 & 0.044 & 0.021 & 0.000 \\
\hline Management, admin. support & 0.030 & 0.041 & 0.038 & 0.062 & 0.038 & 0.561 \\
\hline Educational services & 0.066 & 0.082 & 0.016 & 0.175 & 0.130 & 0.000 \\
\hline Health and social services & 0.108 & 0.122 & 0.002 & 0.109 & 0.200 & 0.043 \\
\hline Information, culture, recreation & 0.042 & 0.041 & 0.083 & 0.032 & 0.030 & 0.087 \\
\hline Accom., food and other services & 0.075 & 0.139 & 0.105 & 0.081 & 0.099 & 0.019 \\
\hline Public administration & 0.078 & 0.029 & 0.035 & 0.100 & 0.057 & 0.000 \\
\hline Not multiple job holder & 0.939 & 0.885 & 0.820 & 0.852 & 0.805 & 0.866 \\
\hline Multiple job holder & 0.061 & 0.115 & 0.180 & 0.148 & 0.195 & 0.134 \\
\hline Not covered by agreement & 0.626 & 0.737 & 0.796 & 0.621 & 0.656 & 0.935 \\
\hline Covered collective agreement & 0.374 & 0.263 & 0.204 & 0.379 & 0.344 & 0.065 \\
\hline Earnings from job ( $\$ 000 /$ year) & 42.400 & 20.400 & 21.600 & 24.820 & 14.240 & 13.280 \\
\hline Unemployment rate (\%) & 8.130 & 8.260 & 10.900 & 8.650 & 9.120 & 7.360 \\
\hline Family income ( $\$ 000 /$ year) & 68.000 & 59.290 & 45.100 & 58.470 & 57.440 & 69.000 \\
\hline Major income earner & 0.692 & 0.469 & 0.562 & 0.526 & 0.371 & 0.318 \\
\hline Spouse or common-law partner & 0.242 & 0.391 & 0.275 & 0.337 & 0.431 & 0.407 \\
\hline Parent of major income earner & 0.009 & 0.019 & 0.018 & 0.010 & 0.017 & 0.000 \\
\hline Child of major income earner & 0.041 & 0.089 & 0.122 & 0.098 & 0.153 & 0.194 \\
\hline Other & 0.016 & 0.033 & 0.023 & 0.027 & 0.028 & 0.081 \\
\hline
\end{tabular}


Table 1 continued

\begin{tabular}{|c|c|c|c|c|c|c|}
\hline \multirow[t]{2}{*}{ Variable } & \multicolumn{2}{|l|}{ Permanent } & \multicolumn{4}{|c|}{ Temporary } \\
\hline & $\begin{array}{l}\text { Full time/ } \\
\text { full year } \\
\text { (1) }\end{array}$ & $\begin{array}{l}\text { Full time/ } \\
\text { part year } \\
\text { and part-time } \\
\text { (2) }\end{array}$ & Seasonal & Term & Casual & Temp-help \\
\hline No social assistance & 0.995 & 0.956 & 0.954 & 0.968 & 0.948 & 0.889 \\
\hline Received social assistance & 0.005 & 0.044 & 0.046 & 0.032 & 0.052 & 0.111 \\
\hline No EI & 0.913 & 0.738 & 0.307 & 0.649 & 0.742 & 0.646 \\
\hline Received EI & 0.087 & 0.262 & 0.693 & 0.351 & 0.258 & 0.354 \\
\hline Firm size $1-19$ & 0.149 & 0.260 & 0.406 & 0.195 & 0.293 & 0.108 \\
\hline Firm size $20-99$ & 0.166 & 0.178 & 0.222 & 0.140 & 0.146 & 0.138 \\
\hline Firm size $100-499$ & 0.156 & 0.118 & 0.113 & 0.119 & 0.092 & 0.000 \\
\hline Firm size 500-999 & 0.072 & 0.050 & 0.038 & 0.054 & 0.059 & 0.000 \\
\hline Firm size over 1000 & 0.388 & 0.261 & 0.102 & 0.341 & 0.234 & 0.124 \\
\hline
\end{tabular}

these estimates are for workers aged 16-69 years and include students. The table shows that $45.9 \%$ of temporary workers make the transition within a year from temporary to permanent work; the percentage is slightly higher for women $(49.7 \%)$ and slightly lower for men $(44.8 \%)$. Over $5 \%$ of permanent workers make the transition from permanent work to temporary work annually.

These estimates of the transition from temporary to permanent work are more than double the estimate provided by Kapsalis and Tourigny (2005) of $17 \%$ which indicates the critical importance of measurement choices. The Kapsalis and Tourigny (2005) estimate refers to the transition rate for individuals aged 16-69 years and from all forms of nonstandard work to standard work, where non-standard work includes part-time permanent work and self-employment, plus the temporary category of work, which is the category of work focused upon in this paper. We infer, therefore, that the transition from the combined group of self-employment and permanent part-time to standard work must be relatively low.

Comparing these transition rates with those of other countries indicates that the transition rate for Canada is in the middle range. The transition rate from temporary to permanent work is estimated to be $18 \%$ for Spain (Amuedo-Dorantes 2000) and $56 \%$ in the US for the transition from temporary help agency work to permanent work (Segal and Sullivan 1997).

Table 2 also demonstrates that the transition rate from temporary to permanent work varies by type of temporary work. The highest rates of transition, for both men and women (58.5\%), are from the specific temporary category "temporary agency"; for male workers in this category, $62.3 \%$ make the transition to permanent work and for female workers in this category, $56.0 \%$ make the transition to permanent work. This is slightly higher than the comparable US transition rate, which is estimated to be 56\% (Segal and Sullivan 1997). For the UK, Booth et al. (2002a, b) find that workers in fixed-term contract positions have higher transition rates, compared to workers in the seasonal-casual temporary category but they do not compare these rates to the temporary agency category. Contrary to our hypothesis that the transition from fixed-term to permanent work would be highest, we found the transition from temporary-help agency work to permanent work to be the highest. 
Table 2 Transition rates between temporary and permanent work status, by gender, annual average for 1999-2004 (\%)

\begin{tabular}{|c|c|c|c|c|c|c|}
\hline \multirow[t]{2}{*}{ Transitions } & \multicolumn{3}{|c|}{$\begin{array}{l}\text { Type } 1 \text { transition } \\
\text { (temporary to permanent) }\end{array}$} & \multicolumn{3}{|c|}{$\begin{array}{l}\text { Type } 2 \text { transition } \\
\text { (permanent to temporary) }\end{array}$} \\
\hline & All & Male & Female & All & Male & Female \\
\hline Temporary (All) & 45.91 & 44.76 & 49.66 & & & \\
\hline Permanent to temporary & & & & 5.52 & 4.91 & 6.22 \\
\hline Seasonal to permanent & 38.89 & 39.22 & 38.37 & & & \\
\hline Permanent to seasonal & & & & 1.39 & 1.74 & 1.01 \\
\hline Term to permanent & 44.65 & 43.72 & 45.42 & & & \\
\hline Permanent to term & & & & 2.11 & 1.71 & 2.57 \\
\hline Temp agency to permanent & 58.53 & 62.33 & 55.97 & & & \\
\hline Permanent to temp agency & & & & 0.09 & 0.08 & 0.10 \\
\hline Casual to permanent & 51.48 & 50.53 & 52.13 & & & \\
\hline Permanent to casual & & & & 1.31 & 0.80 & 1.89 \\
\hline Part-time temporary to permanent & 47.66 & 45.83 & 48.69 & & & \\
\hline Permanent to part-time temporary & & & & 1.13 & 0.52 & 1.83 \\
\hline
\end{tabular}

We also observe that the transition rate from part-time temporary employment to permanent employment is $47.7 \%$, compared to $45.9 \%$ for all temporary workers. This result is somewhat surprising given literature that suggest that, for the UK, part-time temporary men (although not women) have lower transition rates to permanent employment (Booth et al. 2002a, b) and for Australia, which also finds that part-time casuals have lower transition rates compared to full-time casuals (Gaston and Timcke 1999). In addition, the literature on transitions from part-time to full-time work literature finds that full-time work prior to the part-time work substantially increases the chances of moving into full-time work (see O'Reilly and Bothfeld 2002 for the UK and Germany). Thus, we might expect that workers with full-time, rather than part-time temporary work, would be more likely to move into permanent work. However, we do not test for whether the transition is from parttime temporary to part-time permanent or full-time permanent work.

There is some variation over time in the annual transition rate from temporary to permanent work. As shown in Table 3, the transition rate from temporary to permanent work for each annual transition period during the period 1999-2004 ranges from 44.3 for the 2001-2002 period to $54.7 \%$ for $1999-2000$ period. This compares to the transition rate averaged over the five annual transition periods between 1999 and 2004 of $48.7 \%$, as referred to above.

Table 3 Transition rates from temporary work status to permanent work status by time period, annual average for 1999$2004(\%)$

\begin{tabular}{ll}
\hline Time period & Percentage \\
\hline $1999-2000$ & 54.74 \\
$2000-2001$ & 50.51 \\
$2001-2002$ & 44.31 \\
$2002-2003$ & 45.35 \\
$2003-2004$ & 45.40 \\
\hline
\end{tabular}


Given these estimated transition rates from temporary to permanent work in a given year, it indicates that about $50 \%$ of temporary workers in a given year remain in temporary positions. Thus, we estimated of the transition rate for those temporary workers who did not make the transition to permanent work in the first year. For example, when we follow same individuals for 3-year period between 1999 and 2001, the transition rate from temporary to permanent work in $1999-2000$ is $53.5 \%$. Taking the 1999 temporary workers, who remained in temporary employment in 2000 , it is estimated that $37.5 \%$ then make the transition to permanent work between 2000 and 2001. The smaller percentage of temporary workers making the transition to permanent work in the second annual transition period may reflect either the lower skills of these workers or personal choices.

Before moving on to analyze the factors associated with moving out of temporary work and into permanent work, we briefly examine the flow of temporary workers into various labour force states in subsequent years. The results, presented in Table 4, show the percentage of temporary workers who are employed either part-year or full-year in temporary employment in the initial period, to various labour force states such as unemployment, not-in-the labour force, employment full-year, and a combination of these states. The percentages of temporary workers flowing into these different states are averaged over the five transition periods. The results indicate that only a very small number of people who are employed either part-year or full-year as temporary workers in a given year actually move into unemployment or not-in-the labour force states for the full-year in the subsequent period, or a combination of these two states. As shown in Table 4, the percentages of temporary workers moving into these three possible states are reported as nil, given that the numbers are so small that we cannot reliably report them given confidentiality rules. This suggests that temporary employment does not reflect marginal labour force attachment. Almost $61 \%$ of temporary workers who are employed either part-year or full-year in a given period are employed full-year in the subsequent period. The remainder of the temporary workers in a given year move therefore, into one of three states (i) a combination of employment part-year and unemployment part-year, (ii) a combination of employment part-year and non-in-the labour force, or (iii) a combination of employment part-year, unemployment and no-in-the labour force. The first state of employment part-year and unemployment part-year represents the largest percentage of workers at $20.46 \%$.

Table 4 Transition rates from temporary work status to various labour force statuses, annual average for 1999-2004 (\%)

\begin{tabular}{ll}
\hline Labour force status & Percentage \\
\hline Employed all year & 60.89 \\
Unemployed all year & $\mathrm{Nil}$ \\
Not in the labour force all year & $\mathrm{Nil}$ \\
Employed part-year, unemployed part year & 20.46 \\
Employed part-year, not in the labour force part-year & 9.95 \\
Unemployed part-year, not in the labour force part-year & $\mathrm{Nil}$ \\
Employed, unemployed, and not the labour force during year & 8.66 \\
Total & 100.00 \\
Self-employed & 3.08 \\
\hline
\end{tabular}


Table 5 Determinants of transitional probability from temporary employment to permanent employment (marginal effects)

\begin{tabular}{|c|c|c|}
\hline Variable & Marginal effects & $T$-statistics \\
\hline Average probability & 0.465 & \\
\hline \multicolumn{3}{|l|}{ Male } \\
\hline Female & $-0.037 *$ & -1.78 \\
\hline \multicolumn{3}{|l|}{ Non-disabled } \\
\hline Disabled & -0.008 & -0.39 \\
\hline \multicolumn{3}{|l|}{ Not aboriginal } \\
\hline Aboriginal & 0.011 & 0.30 \\
\hline \multicolumn{3}{|l|}{ Not visible minority } \\
\hline Visible minority & -0.009 & -0.23 \\
\hline \multicolumn{3}{|l|}{ Age $20-24$} \\
\hline Age $25-29$ & 0.019 & 0.53 \\
\hline Age $30-39$ & $-0.071 * *$ & -2.13 \\
\hline Age $40-49$ & $-0.136 * * *$ & -4.06 \\
\hline Age $50-59$ & $-0.176^{* * *}$ & -5.01 \\
\hline Age $60-64$ & $-0.314 * * *$ & -7.41 \\
\hline \multicolumn{3}{|l|}{ Single, never married } \\
\hline Married, common law & $0.063^{* *}$ & 2.30 \\
\hline Separated & 0.019 & 0.48 \\
\hline Divorced & 0.053 & 1.29 \\
\hline Widowed & 0.043 & 0.64 \\
\hline Number of children & 0.003 & 0.52 \\
\hline \multicolumn{3}{|l|}{ Less than high school grad. } \\
\hline High school graduate & -0.023 & -1.05 \\
\hline Non-U. postsecondary certif. & 0.006 & 0.25 \\
\hline University degree or certificate & $-0.106 * * *$ & -3.42 \\
\hline \multicolumn{3}{|l|}{ Ontario } \\
\hline Newfoundland/Labrador & $-0.106^{* * *}$ & -3.35 \\
\hline Prince Edward Island & $-0.187 * * *$ & -6.68 \\
\hline Nova Scotia & $-0.065^{* *}$ & -2.50 \\
\hline New Brunswick & $-0.100 * * *$ & -3.78 \\
\hline Quebec & -0.031 & -1.30 \\
\hline Manitoba & 0.019 & 0.59 \\
\hline Saskatchewan & -0.016 & -0.52 \\
\hline Alberta & 0.043 & 1.46 \\
\hline British Columbia & $0.082 * * *$ & 2.70 \\
\hline \multicolumn{3}{|l|}{ Rural } \\
\hline Urban 0-99,999 & $0.035^{* *}$ & 2.00 \\
\hline Urban $100,000-499,999$ & 0.020 & 0.84 \\
\hline Urban 500,000 and higher & -0.007 & -0.29 \\
\hline \multicolumn{3}{|l|}{ Management occupation } \\
\hline Business, finance, admin. & 0.027 & 0.50 \\
\hline Natural and applied science & -0.039 & -0.63 \\
\hline Health & 0.092 & 1.41 \\
\hline
\end{tabular}


Table 5 continued

\begin{tabular}{|c|c|c|}
\hline Variable & Marginal effects & $T$-statistics \\
\hline Social science & -0.073 & -1.28 \\
\hline Art, culture, recreation, sports & -0.077 & -1.11 \\
\hline Sales and service & 0.048 & 0.93 \\
\hline Trades, transport and equip. op. & 0.019 & 0.34 \\
\hline Primary occupations & $-0.142 * *$ & -2.39 \\
\hline Processing, mfg., utilities & 0.047 & 0.76 \\
\hline \multicolumn{3}{|l|}{ Manufacturing industry } \\
\hline Agriculture & 0.020 & 0.32 \\
\hline Forest, fish, mining, oil and gas & -0.050 & -0.98 \\
\hline Utilities & $-0.131^{*}$ & -1.67 \\
\hline Construction & $-0.164 * * *$ & -3.95 \\
\hline Trade & 0.047 & 1.06 \\
\hline Transportation, warehousing & -0.045 & -0.93 \\
\hline Finance, insurance, real estate & 0.011 & 0.19 \\
\hline Prof., scientific, tech. service & -0.044 & -0.80 \\
\hline Management, admin. support & 0.053 & 1.12 \\
\hline Educational services & 0.036 & 0.74 \\
\hline Health and social services & 0.047 & 0.99 \\
\hline Information, culture, recreation & -0.032 & -0.65 \\
\hline Accom., food and other services & 0.015 & 0.34 \\
\hline Public administration & -0.026 & -0.58 \\
\hline \multicolumn{3}{|l|}{ Not multiple job holder } \\
\hline Multiple job holder & 0.011 & 0.59 \\
\hline \multicolumn{3}{|l|}{ Not covered by agreement } \\
\hline Covered collective agreement & $-0.036^{*}$ & -1.82 \\
\hline Earnings from job ( $\$ 000 /$ year) & 0.001 & 1.01 \\
\hline Unemployment rate (\%) & $-0.012 * * *$ & -5.49 \\
\hline Family income (\$000/year) & 0.000 & 0.21 \\
\hline \multicolumn{3}{|l|}{ Major income earner } \\
\hline Spouse or common-law partner & -0.028 & -1.36 \\
\hline Parent of major income earner & -0.002 & -0.02 \\
\hline Child of major income earner & $-0.070^{*}$ & -1.84 \\
\hline Other & -0.018 & -0.29 \\
\hline \multicolumn{3}{|l|}{ Firm size 1-19 } \\
\hline Firm size $20-99$ & -0.010 & -0.43 \\
\hline Firm size $100-499$ & 0.000 & -0.01 \\
\hline Firm size 500-999 & -0.052 & -1.51 \\
\hline Firm size over 1,000 & $-0.049 * *$ & -2.06 \\
\hline Number of observations & 9,335 & \\
\hline
\end{tabular}

Note: Significance is denoted by $* * * 0.01$ level, $* * 0.05$ level and $* 0.10$ level. $P$-values are in accompanying Appendix table 
Turning now to factors associated with the transition from temporary to permanent work, the results of the transition model outlined in Sect. 3 are presented in Tables 5-7. After controlling for factors in all three categories, women have a lower likelihood, compared to men, of making the transition from temporary to permanent work. For example, as shown in Table 5 (column 1), the marginal effect of the female variable is -0.037 , indicating that the transition rate for women is $3.7 \%$ lower than for men, and this is statistically significant at the $10 \%$ level. Examining the results separately for each type of temporary work (not reported in the tables), we found that women had lower transition probabilities to permanent work, from each type of temporary work with the exception of temporary part-time work to permanent. The finding that women have lower transition probabilities compared to men is consistent with the hypothesis outlined in Sect. 2.

The results of the transition model estimated separately for men and women are presented in Tables 6 and 7, respectively.

Starting with human capital factors, there is mixed support for the human capital hypothesis that workers with greater amounts of human capital will have higher transition rates into permanent employment. In the Probit model, surprisingly, high school graduates, compared to workers without a high school diploma, are no more likely to make the transition to permanent work. Notice that for both men and women the education variables are not statistically significant, with the exception of a university degree and this has a negative sign. However, the results on the transition rates from temporary to permanent work status by level of education, not controlling for other factors, are more in line with the human capital hypotheses. As shown in Table 8, the transition rate from temporary to permanent work is lowest for temporary workers without a high school diploma; for this group of temporary workers, the transition rate is $43.8 \%$ compared to $50.5 \%$ for workers with a high school diploma and $44.1 \%$ for workers with a university degree.

The finding from the Probit model estimation that temporary workers with a university degree have lower transition rates than workers with no high school diploma is perhaps offset by the potentially better working conditions and pay associated with the jobs taken by the temporary workers with a university degree.

In terms of household structure and demographics, we find some support for the hypotheses. We found that in general, older workers have a lower likelihood of making the transition from temporary to permanent work. For men, each successively older age group has a lower probability of making the transition from temporary to permanent work. For example, male workers aged 40-49 years of age, have a $16.8 \%$ lower chance of making the transition compared to workers aged 20-24 years of age and workers aged 50-59 years of age have a $22.3 \%$ lower probability of making the transition, compared to workers aged 20-24 years of age. ${ }^{9}$ Generally, the finding that younger workers in Canada have higher transition probabilities from temporary to permanent work is consistent with the findings from other countries (Chalmers and Kalb 2001, for men in the UK, see Booth et al. 2002b).

\footnotetext{
9 The result that older workers are less likely to make the transition to permanent worker than younger workers appears to run counter to a human capital hypothesis that older workers, given their greater labour market experience, should have higher rates of transition to permanent work. On the other hand, employers may be more reluctant to make investment in older workers in temporary work arrangement and offer them permanent positions due to their shorter career horizon for employers to recoup the costs of hiring and training (Hutchens 1986).
} 
Table 6 Determinants of transitional probability from temporary employment to permanent employment (marginal effects): male sample

\begin{tabular}{|c|c|c|}
\hline Variable & Marginal effects & $T$-statistics \\
\hline Average probability & 0.451 & \\
\hline \multicolumn{3}{|l|}{ Non-disabled } \\
\hline Disabled & -0.034 & -1.17 \\
\hline \multicolumn{3}{|l|}{ Not aboriginal } \\
\hline Aboriginal & -0.038 & -0.78 \\
\hline \multicolumn{3}{|l|}{ Not visible minority } \\
\hline Visible minority & 0.049 & 0.80 \\
\hline \multicolumn{3}{|l|}{ Age $20-24$} \\
\hline Age $25-29$ & 0.016 & 0.32 \\
\hline Age $30-39$ & -0.066 & -1.45 \\
\hline Age $40-49$ & $-0.168 * * *$ & -3.60 \\
\hline Age 50-59 & $-0.223 * * *$ & -4.56 \\
\hline Age $60-64$ & $-0.344 * * *$ & -6.26 \\
\hline \multicolumn{3}{|l|}{ Single, never married } \\
\hline Married, common law & $0.089 * *$ & 2.42 \\
\hline Separated & 0.001 & 0.01 \\
\hline Divorced & $0.107 *$ & 1.74 \\
\hline Widowed & -0.123 & -1.06 \\
\hline Number of children & 0.010 & 1.09 \\
\hline \multicolumn{3}{|l|}{ Less than high school grad. } \\
\hline High school graduate & -0.027 & -0.93 \\
\hline Non-U. postsecondary certif. & -0.007 & -0.25 \\
\hline University degree or certificate & $-0.105 * *$ & -2.20 \\
\hline \multicolumn{3}{|l|}{ Ontario } \\
\hline Newfoundland/Labrador & $-0.154 * * *$ & -3.47 \\
\hline Prince Edward Island & $-0.198 * * *$ & -4.97 \\
\hline Nova Scotia & $-0.066^{*}$ & -1.75 \\
\hline New Brunswick & $-0.175^{* * *}$ & -4.63 \\
\hline Quebec & $-0.065^{*}$ & -1.86 \\
\hline Manitoba & 0.061 & 1.25 \\
\hline Saskatchewan & $-0.087 * *$ & -2.02 \\
\hline Alberta & 0.015 & 0.34 \\
\hline British Columbia & $0.119 * * *$ & 2.67 \\
\hline \multicolumn{3}{|l|}{ Rural } \\
\hline Urban 0-99,999 & -0.021 & -0.85 \\
\hline Urban $100,000-499,999$ & -0.008 & -0.24 \\
\hline Urban 500,000 and higher & -0.046 & -1.30 \\
\hline \multicolumn{3}{|l|}{ Management occupation } \\
\hline Business, finance, admin. & -0.016 & -0.19 \\
\hline Natural and applied science & $-0.144^{*}$ & -1.86 \\
\hline Health & 0.173 & 1.24 \\
\hline Social science & -0.121 & -1.43 \\
\hline Art, culture, recreation, sports & -0.121 & -1.22 \\
\hline
\end{tabular}


Table 6 continued

\begin{tabular}{|c|c|c|}
\hline Variable & Marginal effects & $T$-statistics \\
\hline Sales and service & 0.021 & 0.28 \\
\hline Trades, transport and equip. op. & -0.004 & -0.06 \\
\hline Primary occupations & $-0.199 * * *$ & -2.68 \\
\hline Processing, mfg., utilities & 0.040 & 0.48 \\
\hline \multicolumn{3}{|l|}{ Manufacturing industry } \\
\hline Agriculture & -0.029 & -0.37 \\
\hline Forest, fish, mining, oil and gas & -0.078 & -1.30 \\
\hline Utilities & $-0.159 *$ & -1.66 \\
\hline Construction & $-0.213 * * *$ & -4.42 \\
\hline Trade & -0.010 & -0.17 \\
\hline Transportation, warehousing & -0.076 & -1.27 \\
\hline Finance, insurance, real estate & 0.044 & 0.44 \\
\hline Prof., scientific, tech. service & 0.003 & 0.04 \\
\hline Management, admin. support & 0.007 & 0.11 \\
\hline Educational services & -0.037 & -0.48 \\
\hline Health and social services & -0.024 & -0.26 \\
\hline Information, culture, recreation & -0.080 & -1.22 \\
\hline Accom., food and other services & -0.005 & -0.08 \\
\hline Public administration & 0.030 & 0.49 \\
\hline \multicolumn{3}{|l|}{ Not multiple job holder } \\
\hline Multiple job holder & 0.000 & 0.00 \\
\hline \multicolumn{3}{|l|}{ Not covered by agreement } \\
\hline Covered collective agreement & -0.010 & -0.37 \\
\hline Earnings from job ( $\$ 000 /$ year) & 0.000 & 0.48 \\
\hline Unemployment rate (\%) & $-0.011 * * *$ & -3.51 \\
\hline Family income (\$000/year) & 0.001 & 1.34 \\
\hline \multicolumn{3}{|l|}{ Major income earner } \\
\hline Spouse or common-law partner & 0.025 & 0.84 \\
\hline Parent of major income earner & 0.156 & 1.51 \\
\hline Child of major income earner & -0.064 & -1.36 \\
\hline Other & -0.066 & -0.85 \\
\hline \multicolumn{3}{|l|}{ Firm size $1-19$} \\
\hline Firm size 20-99 & -0.048 & -1.54 \\
\hline Firm size $100-499$ & -0.035 & -0.93 \\
\hline Firm size 500-999 & -0.076 & -1.40 \\
\hline Firm size over 1000 & $-0.099 * * *$ & -2.80 \\
\hline Number of observations & 4,529 & \\
\hline
\end{tabular}

Note: Significance is denoted by *** 0.01 level, $* * 0.05$ level and $* 0.10$ level. $P$-values are in accompanying Appendix table

We also find that the relationship between age and transition probabilities is similar across the different types of temporary work.

Marital status, for men, is associated with a positive impact on the probability of making the transition from temporary to permanent work. For example, the coefficient on the 
Table 7 Determinants of transitional probability from temporary employment to permanent employment (marginal effects): female sample

\begin{tabular}{|c|c|c|}
\hline Variable & Marginal effects & $T$-statistics \\
\hline Average probability & 0.482 & \\
\hline \multicolumn{3}{|l|}{ Non-disabled } \\
\hline Disabled & -0.000 & -0.01 \\
\hline \multicolumn{3}{|l|}{ Not aboriginal } \\
\hline Aboriginal & 0.062 & 1.16 \\
\hline \multicolumn{3}{|l|}{ Not visible minority } \\
\hline Visible minority & -0.061 & -1.19 \\
\hline \multicolumn{3}{|l|}{ Age $20-24$} \\
\hline Age $25-29$ & 0.020 & 0.41 \\
\hline Age $30-39$ & $-0.094 * *$ & -1.99 \\
\hline Age $40-49$ & $-0.118 * *$ & -2.43 \\
\hline Age $50-59$ & $-0.150 * * *$ & -2.99 \\
\hline Age $60-64$ & $-0.312^{* * *}$ & -4.78 \\
\hline \multicolumn{3}{|l|}{ Single, never married } \\
\hline Married, common law & 0.011 & 0.26 \\
\hline Separated & -0.005 & -0.09 \\
\hline Divorced & -0.007 & -0.13 \\
\hline Widowed & 0.007 & 0.09 \\
\hline Number of children & -0.002 & -0.22 \\
\hline \multicolumn{3}{|l|}{ Less than high school grad. } \\
\hline High school graduate & -0.019 & -0.54 \\
\hline Non-U. postsecondary certif. & 0.003 & 0.09 \\
\hline University degree or certificate & $-0.133 * * *$ & -3.06 \\
\hline \multicolumn{3}{|l|}{ Ontario } \\
\hline Newfoundland/Labrador & -0.057 & -1.26 \\
\hline Prince Edward Island & $-0.183 * * *$ & -4.68 \\
\hline Nova Scotia & $-0.086 * *$ & -2.36 \\
\hline New Brunswick & -0.025 & -0.67 \\
\hline Quebec & 0.005 & 0.17 \\
\hline Manitoba & -0.011 & -0.26 \\
\hline Saskatchewan & 0.059 & 1.37 \\
\hline Alberta & 0.065 & 1.63 \\
\hline British Columbia & 0.053 & 1.31 \\
\hline \multicolumn{3}{|l|}{ Rural } \\
\hline Urban 0-99,999 & $0.088 * * *$ & 3.62 \\
\hline Urban $100,000-499,999$ & 0.046 & 1.37 \\
\hline Urban 500,000 and higher & 0.028 & 0.88 \\
\hline \multicolumn{3}{|l|}{ Management occupation } \\
\hline Business, finance, admin. & 0.055 & 0.73 \\
\hline Natural and applied science & 0.048 & 0.47 \\
\hline Health & 0.074 & 0.88 \\
\hline Social science & -0.050 & -0.63 \\
\hline Art, culture, recreation, sports & -0.022 & -0.23 \\
\hline
\end{tabular}


Table 7 continued

\begin{tabular}{|c|c|c|}
\hline Variable & Marginal effects & $T$-statistics \\
\hline Sales and service & 0.054 & 0.73 \\
\hline Trades, transport and equip. op. & -0.058 & -0.62 \\
\hline Primary occupations & -0.027 & -0.24 \\
\hline Processing, mfg., utilities & 0.071 & 0.75 \\
\hline \multicolumn{3}{|l|}{ Manufacturing industry } \\
\hline Agriculture & 0.080 & 0.76 \\
\hline Forest, fish, mining, oil and gas & 0.080 & 0.82 \\
\hline Utilities & -0.091 & -0.72 \\
\hline Construction & -0.027 & -0.28 \\
\hline Trade & $0.130^{* *}$ & 2.01 \\
\hline Transportation, warehousing & 0.058 & 0.70 \\
\hline Finance, insurance, real estate & 0.059 & 0.79 \\
\hline Prof., scientific, tech. service & -0.017 & -0.23 \\
\hline Management, admin. support & 0.110 & 1.59 \\
\hline Educational services & $0.119^{*}$ & 1.75 \\
\hline Health and social services & $0.152 * *$ & 2.35 \\
\hline Information, culture, recreation & 0.064 & 0.87 \\
\hline Accom., food and other services & 0.099 & 1.51 \\
\hline Public administration & -0.030 & -0.45 \\
\hline \multicolumn{3}{|l|}{ Not multiple job holder } \\
\hline Multiple job holder & 0.034 & 1.37 \\
\hline \multicolumn{3}{|l|}{ Not covered by agreement } \\
\hline Covered collective agreement & $-0.057 * *$ & -2.05 \\
\hline Earnings from job ( $\$ 000 /$ year) & 0.000 & 0.24 \\
\hline Unemployment rate (\%) & $-0.013 * * *$ & -4.29 \\
\hline Family income ( $\$ 000 /$ year) & 0.000 & -0.02 \\
\hline \multicolumn{3}{|l|}{ Major income earner } \\
\hline Spouse or common-law partner & $-0.053^{*}$ & -1.71 \\
\hline Parent of major income earner & -0.046 & -0.46 \\
\hline Child of major income earner & $-0.113^{*}$ & -1.88 \\
\hline Other & 0.070 & 0.76 \\
\hline \multicolumn{3}{|l|}{ Firm size $1-19$} \\
\hline Firm size $20-99$ & 0.033 & 0.96 \\
\hline Firm size $100-499$ & 0.054 & 1.42 \\
\hline Firm size 500-999 & -0.011 & -0.24 \\
\hline Firm size over 1000 & 0.017 & 0.53 \\
\hline Number of observations & 4,802 & \\
\hline
\end{tabular}

Note: Significance is denoted by *** 0.01 level, $* * 0.05$ level and $* 0.10$ level. $P$-values are in accompanying Appendix table

married variable for men is 0.089 indicating that married men have an $8.9 \%$ higher probability of making the transition to permanent work compared to single men. For women, marital status is not a statistically significant determinant of the transition rate. 
Table 8 Transition rates from temporary work status to permanent work status by level of education, annual average for 1999-2004 (\%)

\begin{tabular}{lc}
\hline Level of education & Percentage \\
\hline Less than high school graduation & 43.83 \\
High school graduate & 50.51 \\
Non-U. postsecondary certificate & 51.70 \\
University degree or certificate & 44.09 \\
\hline
\end{tabular}

The number of children, disabled status, aboriginal status, and visible minority status are not statistically significant determinants of the transition probability from temporary to permanent work for either men or women. Family income is also not a statistically significant determinant of the transition probability for either men or women.

Turning to labour market segmentation factors affecting the demand for temporary workers, only some of the results are consistent with hypotheses outlined above. In contrast with the hypothesis that unionization is associated with greater probability of making the transition to permanent work, we found that for women, being covered by a collective agreement reduces the probability of moving into permanent work. Note that the coefficient on the collective agreement variable is -0.057 which indicates that being covered by a collective agreement reduces the probability of making the transition by $5.7 \%$. The collective agreement variable is not statistically significant in the male regression.

Also contrary to the literature, we did not find a consistent positive relationship between firm size and transition probability. Firm size affects transition rates of men and women quite differently. For men, larger firm size (over 1,000 employees) is associated with a lower and statistically significant transition rate. Whereas for women, none of the firm size variables are statistically significant.

Finally, the unemployment rate is negatively related to the probability of making the transition from temporary permanent work for both men and women. For example, a $1 \%$ increase in the unemployment is associated with a $1.3 \%$ decrease in the probability of making the transition from temporary to permanent work for women; for men, an increase in the unemployment rate by $1 \%$ is associated with a reduction of $1.1 \%$ in transition probability. The unemployment rate is a statistically significant determinant of the transition rate for each of the sub-categories of temporary work.

\section{Conclusion}

Temporary work is often involuntary and is associated with greater economic insecurity compared to permanent work. The insecurity arises from the non-permanency of the employment contract which is compounded by the tendency for temporary jobs to be associated with lower wages, access to benefits, and on-the-job training, compared to permanent jobs (as discussed in the literature).

Undertaking temporary work does enable almost one-half of temporary workers to move into permanent work, over the period of a year. However, women are $(3.7 \%)$ less likely than men to make the transition to permanent work in a given year. Of those remaining in temporary employment after the initial period, roughly one-third make the 
transition to permanent employment in the subsequent period. Given that our sample, defined as workers aged 20-64 years and excluding students, likely reflects the group of workers most fully attached to the labour market, these estimates should be taken as upper bounds on the temporary to permanent transition rates. In addition, almost $40 \%$ of temporary workers will experience either unemployment, a period out of the labour force, or a combination of these two states. So while after 2 years, the majority of temporary workers will have made the transition to permanent work, many will have experienced high degrees of economic insecurity in the interim period and some workers will not be able to make the transition.

Three sets of factors to explain transition probabilities to permanent work were examined. Surprisingly, human capital factors were not strongly associated with higher transition probabilities to permanent work, as indicated in the Probit model. Although transition rates by education level, not controlling for other factors such as occupation, are more in line with the human capital expectations. Within the household structure and demographic factors, age had the most consistent relationship with transition probabilities, and specifically, older workers were found to be less likely to make the transition to permanent work. With respect to labour market segmentation factors, unionization and firm size were not found to be strong predictors of the transition probability. The unemployment rate, however, was found to be a statistically significant predictor of transition into permanent work. This finding is consistent with the literature which generally indicates transition rates are pro-cyclical.

Temporary employment and its transitions deserve some policy attention given the general economic insecurity associated with temporary work. It is interesting to note that older workers and female workers are less likely to make transitions from temporary to permanent employment; at the same time, married men, but not married women, are more likely to do so. This may suggest that public policies that facilitate work-life balance and firm-specific investment on older workers may help married women and older workers move out of temporary work arrangements.

This analysis of the transition from temporary work to permanent work extends the Canadian literature in two main ways. First, the transition rates are examined by gender and by type of temporary work category. Second, the study provides a multivariate analysis of which workers are most likely to make the transition and the demand side factors associated with the transition.

Future work could focus on examining factors associated with transitions to other labour force states including out-of-the-labour force, unemployment, and self-employment. A second line of investigation would be to assess the duration of temporary employment using a hazard rate approach. Finally, given the lack of support for the human capital hypothesis tested with broad education groups in the Probit model, future work might fruitfully examine whether an improvement in human capital among the less educated temporary workers is associated with a greater transition to permanent employment, and whether other factors, such as unobserved individual heterogeneity and employee self selection or employer selection, may also affect temporary to permanent employment transitions. Based on the results presented here, future work should be careful about generalizing across genders and types of temporary sub-categories.

Acknowledgements The authors thank Workshop participants for helpful comments, especially David Green. 


\section{Appendix A}

Means for main variables of interest for the whole sample and for sub-samples by gender

\begin{tabular}{|c|c|c|c|}
\hline Variable & Whole sample & Male sample & Female sample \\
\hline Female & 0.479 & & \\
\hline \multicolumn{4}{|l|}{ Non-disabled } \\
\hline Disabled & 0.143 & 0.137 & 0.150 \\
\hline \multicolumn{4}{|l|}{ Not aboriginal } \\
\hline Aboriginal & 0.031 & 0.029 & 0.032 \\
\hline \multicolumn{4}{|l|}{ Not visible minority } \\
\hline Visible minority & 0.098 & 0.096 & 0.100 \\
\hline Age $20-24$ & 0.054 & 0.056 & 0.051 \\
\hline Age $25-29$ & 0.107 & 0.107 & 0.107 \\
\hline Age $30-39$ & 0.296 & 0.300 & 0.293 \\
\hline Age $40-49$ & 0.329 & 0.324 & 0.334 \\
\hline Age $50-59$ & 0.189 & 0.185 & 0.192 \\
\hline Age $60-64$ & 0.026 & 0.028 & 0.023 \\
\hline \multicolumn{4}{|l|}{ Single, never married } \\
\hline Married, common law & 0.712 & 0.721 & 0.702 \\
\hline Separated & 0.037 & 0.031 & 0.044 \\
\hline Divorced & 0.055 & 0.040 & 0.070 \\
\hline Widowed & 0.009 & 0.003 & 0.015 \\
\hline Number of children & 1.553 & 1.508 & 1.602 \\
\hline \multicolumn{4}{|l|}{ Less than high school grad. } \\
\hline High school graduate & 0.298 & 0.295 & 0.301 \\
\hline Non-U. postsecondary certif. & 0.348 & 0.337 & 0.360 \\
\hline University degree or certificate & 0.214 & 0.208 & 0.220 \\
\hline Work experience (years) & 16.76 & 0.008 & 14.720 \\
\hline \multicolumn{4}{|l|}{ Ontario } \\
\hline Newfoundland/Labrador & 0.018 & 0.018 & 0.018 \\
\hline Prince Edward Island & 0.005 & 0.005 & 0.005 \\
\hline Nova Scotia & 0.033 & 0.033 & 0.034 \\
\hline New Brunswick & 0.028 & 0.027 & 0.030 \\
\hline Quebec & 0.252 & 0.254 & 0.250 \\
\hline Manitoba & 0.037 & 0.036 & 0.039 \\
\hline Saskatchewan & 0.029 & 0.028 & 0.031 \\
\hline Alberta & 0.103 & 0.101 & 0.104 \\
\hline British Columbia & 0.117 & 0.119 & 0.115 \\
\hline \multicolumn{4}{|l|}{ Rural } \\
\hline Urban 0-99,999 & 0.242 & 0.245 & 0.239 \\
\hline Urban $100,000-499,999$ & 0.128 & 0.125 & 0.131 \\
\hline Urban 500,000 and higher & 0.446 & 0.444 & 0.448 \\
\hline \multicolumn{4}{|l|}{ Management occupation } \\
\hline Business, finance, admin. & 0.201 & 0.101 & 0.309 \\
\hline Natural and applied science & 0.074 & 0.114 & 0.030 \\
\hline
\end{tabular}


Appendix continued

\begin{tabular}{|c|c|c|c|}
\hline Variable & Whole sample & Male sample & Female sample \\
\hline Health & 0.058 & 0.016 & 0.104 \\
\hline Social science & 0.076 & 0.048 & 0.106 \\
\hline Art, culture, recreation, sports & 0.021 & 0.018 & 0.024 \\
\hline Sales and service & 0.223 & 0.177 & 0.274 \\
\hline Trades, transport and equip. op. & 0.147 & 0.263 & 0.020 \\
\hline Primary occupations & 0.022 & 0.035 & 0.008 \\
\hline Processing, mfg., utilities & 0.092 & 0.123 & 0.058 \\
\hline \multicolumn{4}{|l|}{ Manufacturing industry } \\
\hline Agriculture & 0.010 & 0.011 & 0.008 \\
\hline Forest, fish, mining, oil and gas & 0.022 & 0.035 & 0.007 \\
\hline Utilities & 0.011 & 0.016 & 0.005 \\
\hline Construction & 0.053 & 0.091 & 0.012 \\
\hline Trade & 0.142 & 0.136 & 0.148 \\
\hline Transportation, warehousing & 0.049 & 0.069 & 0.027 \\
\hline Finance, insurance, real estate & 0.058 & 0.041 & 0.077 \\
\hline Prof., scientific, tech. service & 0.053 & 0.054 & 0.052 \\
\hline Management, admin. support & 0.032 & 0.030 & 0.034 \\
\hline Educational services & 0.079 & 0.047 & 0.113 \\
\hline Health and social services & 0.112 & 0.037 & 0.195 \\
\hline Information, culture, recreation & 0.043 & 0.045 & 0.041 \\
\hline Accom., food and other services & 0.087 & 0.069 & 0.107 \\
\hline Public administration & 0.072 & 0.082 & 0.061 \\
\hline \multicolumn{4}{|l|}{ Not multiple job holder } \\
\hline Multiple job holder & 0.085 & 0.075 & 0.096 \\
\hline \multicolumn{4}{|l|}{ Not covered by agreement } \\
\hline Covered collective agreement & 0.354 & 0.367 & 0.340 \\
\hline Earnings from job ( $\$ 000 /$ year) & 34.118 & 41.000 & 26.624 \\
\hline Unemployment rate $(\%)$ & 7.990 & 8.011 & 7.967 \\
\hline Family income (\$000/year) & 61.903 & 62.994 & 60.715 \\
\hline \multicolumn{4}{|l|}{ Major income earner } \\
\hline Spouse or common-law partner & 0.304 & 0.122 & 0.503 \\
\hline Parent of major income earner & 0.008 & 0.005 & 0.011 \\
\hline Child of major income earner & 0.046 & 0.054 & 0.038 \\
\hline Other & 0.015 & 0.017 & 0.014 \\
\hline \multicolumn{4}{|l|}{ Firm size $1-19$} \\
\hline Firm size $20-99$ & 0.169 & 0.174 & 0.164 \\
\hline Firm size $100-499$ & 0.144 & 0.150 & 0.138 \\
\hline Firm size $500-999$ & 0.075 & 0.074 & 0.076 \\
\hline Firm size over 1000 & 0.348 & 0.355 & 0.339 \\
\hline Number of observations & 62,000 & 31,215 & 30,785 \\
\hline
\end{tabular}




\section{References}

Amuedo-Dolantes, C. (2000). Work transitions into and out of involuntary temporary employment in a segmented market: Evidence from Spain. Industrial and Labor Relations Review, 55(2), 309-325.

Baker, D., Glyn, A., Howell, D., \& Schmitt, J. (2004). Unemployment and labor market institutions: The failure of the empirical case for deregulation. Report to the International Labour Organization and available at http://www.newschool.edu/cepa/.

Bentolila, S., \& Dolado, J. J. (1994). Labour flexibility and wages: Lessons from Spain. Economic Policy, 18, 54-99.

Blanchard, O., \& Landier, A. (2001). The perverse effects of partial labour market reform: Fixed term contracts in France. Economic Journal, 112, 829-853.

Blank, R. (1994). The dynamics of part-time work. NBER, Working Paper No. 4911.

Booth, A. L., Dolado, J. J., \& Frank, J. (2002a). Symposium on temporary work: Introduction. Economic Journal, 112, F181-F188.

Booth, A. L., Francesconi, M., \& Frank, J. (2002b). Temporary jobs: Stepping stones or dead ends?. Economic Journal, 112, F189-F213.

Campbell, I., \& Burgess, J. (2001). Casual employment in Australia and temporary employment in Europe: Developing a cross-national comparison. Work, Employment \& Society, 15(1), 171-184.

Chalmers, J., \& Kalb, G. (2001). Moving from unemployment to permanent employment: Could a casual job accelerate the transition? Australian Economic Review, 34(4), 415-436.

Doeringer, P. B., \& Piore, M. J. (1971). Internal labor markets and manpower analysis. Lexington: D.C. Heath.

Fuller, S., \& Vosko, L. (2008). Temporary employment and social inequality in Canada: Exploring intersections of gender, race, and immigration status.

Galarneau, D. (2005). Earnings of temporary versus permanent employees. Perspectives on Labour and Income, 17(1), 40-53.

Gaston, N., \& Timcke, D. (1999). Do casual workers find permanent full-time employment? Evidence from the Australian Youth Survey. The Economic Record, 75(231), 333-347.

Holmlund, B., \& Storrie, D. (2002). Temporary work in turbulent times: The Swedish experience. Economic Journal, 112(480), F245-F269.

Hutchens, R. (1986). Delayed payment contracts and firm's propensity to hire older workers. Journal of Labor Economics, 4(4), 439-457.

Janz, T. (2004). Low-paid employment and 'moving up'. Income Statistics Division, Income research paper series, Statistics Canada.

Kapsalis, C., \& Tourigny, P. (2005). Duration of non-standard employment. Perspectives on Labour and Income, 17(1), 31-39.

MacPhail, F., \& Bowles, P. (2008). Temporary work and neoliberal government policy: Evidence from British Columbia, Canada. International Review of Applied Economics.

Morissette, R., \& Johnson, A. (2005). Are good jobs disappearing in Canada? Analytical Studies Research Paper Series, No. 239. Statistics Canada.

Noreau, N. (2000). Longitudinal aspect of involuntary part-time employment. Income Statistics Division, Statistics Canada.

O'Reilly, J., \& Bothfeld, S. (2002). What happens after working part time? Integration, maintenance or exclusionary transitions in Britain and western Germany. Cambridge Journal of Economics, 26, 409-439.

Polivka, A. E. (1996). Into contingent and alternative employment: by choice? Monthly Labor Review, $119(10), 55-74$

Segal, L. M., \& Sullivan, D. G. (1997). The growth of temporary services work. Journal of Economic Perspectives, 11(2), 117-136.

Vosko, L., Zukewich, N., \& Cranford, C. (2003). Precarious jobs: A new typology of employment. Perspectives on Labour and Income, 15(5), 39-49.

Wiens-Tuers, B. A. (2001). Employee attachment and temporary workers. Journal of Economic Issues, $35(1), 45-48$. 